\title{
Trabalhonecessário
}

ISSN: 1808 - 799X

ANO 12, № 19 - 2014

\section{POLÍTICAS PÚBLICAS PARA O EMPREENDEDORISMO EM TEMPOS DE PRECARIZAÇÃO DO TRABALHO}

\author{
Mari Fusioka ${ }^{1}$ \\ Adreana Dulcina Platt ${ }^{2}$
}

\begin{abstract}
Resumo
Fundamentado no paradigma toyotista, a reestruturação do setor produtivo ocorrida no final do século XX levou à quebra das cadeias produtivas e, consequentemente, à terceirização dos serviços. Tal processo objetivou a redução dos custos trabalhistas e transformou os trabalhadores assalariados em pequenos fornecedores. Este modelo conhecido como out-sourcing ocorre na atualidade de forma mundial, exigindo dos Estados o estabelecimento de estratégias nas políticas públicas para atrair os investimentos estrangeiros. Frente a este novo cenário, a orientação e a capacitação profissional passaram a ser concebidas como um dos fatores para o êxito das políticas públicas e privadas, na qual o Estado e a sociedade civil devem atuar de forma combinada com o propósito de facilitar a atuação dos investidores estrangeiros na localidade. É neste contexto que a formação voltada para o empreendedorismo torna-se parte da agenda das políticas públicas. Este artigo mostra que o empreendedorismo, na realidade, configura-se em uma nova forma de precarização do trabalho com a finalidade de recuperar o padrão de acumulação e, contrariamente à concepção propalada pelas Agências Multilaterais, potencializam os antagonismos sociais.
\end{abstract}

Palavras-chave: Empreendedorismo; Políticas públicas de educação; Precarização do trabalho.

\section{PUBLIC POLICIES FOR ENTREPRENEURSHIP IN TIMES OF PRECARIOUS WORK}

\footnotetext{
${ }^{1}$ Mestre em Educação pela UEL, 2014. marifusioka@bol.com.br

2 Doutora em Educação pela Universidade Estadual de Campinas (área: História, Filosofia e Educação - 2004) e Pós-Doutora em Ciências Humanas pela Universidade Federal de Santa Catarina (Doutorado Interdisciplinar em Ciências Humanas - 2012). Professora do departamento de Educação da Universidade Estadual de Londrina. adplatt@uel.br
} 


\title{
Trabalhonecessário
}

ISSN: 1808 - 799X

ANO 12, № 19 - 2014

\begin{abstract}
Based on toyotist paradigm, the restructuring of the productive sector occurred in the late twentieth century led to the breakdown of the productive chains and, consequently, the outsourcing of services. This process aimed at labor costs reductions and become salaried workers in small suppliers. This model known as "out-sourcing" occurs in the present world order, requiring States to establish strategies in public policies to attract foreign investment. Faced with this new economic order, the guidance and professional training came to be conceived as one of the factors for the success of public and private policies, in which the state and civil society must act in combination with the purpose of facilitating the activities of foreign investors in the locality. It's in this context that the training focused on entrepreneurship becomes part of the public policy agenda. This paper shows that entrepreneurship, in fact, appears in a new form of precarious work in order to recover the pattern of accumulation and, contrarily to vaunted conception by Multilateral Agencies, leverage social antagonisms.
\end{abstract}

Keywords: Entrepreneurship; Public policy on education; Precarious work.

\section{Introdução}

Atualmente, os Estados (no sentido local, regional ou nacional), alicerçados no conceito de vantagem competitiva ${ }^{3}$, estabelecem estratégias de políticas públicas para atrair os investimentos estrangeiros em um ambiente altamente competitivo, em um cenário internacional no qual há poucas barreiras geográficas e abundante reserva de mão de obra, cabendo, então, tanto oferecer condições vantajosas para os negócios, como fornecer força de trabalho em quantidade e qualidade, garantida por meio da formação profissional e treinamento (HARVEY, 2011, p. 60). Tal cenário resulta da reestruturação produtiva, ocorrida com maior

\footnotetext{
${ }^{3}$ A expressão "vantagem competitiva" foi cunhada por Michel Porter (teórico americano) nos anos 1980. "Em suma, sua teoria dizia que as organizações (e nações) deveriam buscar o desenvolvimento de produtos de alta qualidade para serem vendidos por preços mais altos que os dos concorrentes. E isso aconteceria quando uma organização desenvolve um atributo ou combinação destes que a permitiria se sobressair frente à concorrência" (SCATENA 2013, s/p.).
} 


\section{Trabalhonecessário}

ISSN: 1808 - 799X

ANO 12, № 19 - 2014

intensidade a partir da década de $1990^{4}$, quando a quebra das cadeias produtivas demandou a criação de localidades, que garantiu a realocação espacial dos excedentes de capital ociosos para investimento produtivo e lucrativo (HARVEY, 2005, p. 124).

Silver (2005, p. 83), defende que além do deslocamento espacial, os capitalistas responderam a um estrangulamento dos lucros inovando em processos tecnológicos e/ou organizacional. Neste sentido, a crise nas décadas de 70 e 80 demandou também a implantação de um novo modelo organizacional, que garantiu novos padrões de acumulação capitalista: o toyotismo. Neste modelo, a organização da empresa se dá de forma desverticalizada, ou seja, ela passa por um amplo processo de subcontratação e terceirizações da atividademeio (out-sourcing), tanto de bens materiais como de serviços, objetivando a redução dos custos e a máxima produtividade. É fundamentado nesta premissa que ocorreu a quebra das cadeias produtivas, pela qual as terceirizações passaram a acontecer em âmbito global. Assim, as localidades representaram a materialização tanto de um novo modelo de soluções espaciais como organizacional.

Diante de tal contexto surgirá a necessidade da criação de programas orientados ao empreendedorismo e, consequentemente, as políticas orientadas

\footnotetext{
${ }^{4}$ Nos anos 1990, presenciou-se no Brasil a explosão da abertura de microempresas ${ }^{4}$. Para Naretto, Botelho e Mendonça (2004, p. 68): Esse movimento, semelhante ao visto nos países avançados, pareceu associar-se, sobretudo aos processos de terceirização e à quebra de cadeias produtivas nas aglomerações industriais até então integradas, processos movidos em geral pela redução de custos via especialização produtiva e via transformação de trabalhadores assalariados em pequenos fornecedores, como meio de contenção dos custos trabalhistas. Isto ocorre no contexto das reformas do Estado (voltado para a acumulação de capital) - quando há um amplo processo de flexibilização das relações de trabalho e precarização do direito e das proteções ao trabalhador, como das condições de trabalho garantidas até então por meio de regulamentação Estatal, levando à retração do emprego. Portanto, por meio da terceirização, as corporações apropriaram-se do exército industrial de reserva - resultante do amplo processo de precarização do trabalho - porém, agora, na forma de pessoas jurídicas, ou seja, como pequenas e micro empresas (PMEs).
} 


\section{Trabalhonecessário}

ISSN: 1808 - 799X

ANO 12, № 19 - 2014

pelo Estado voltadas às localidades passam a ganhar relevância nas agendas dos países e das organizações internacionais. Isto porque, em conformidade com o pensamento neoliberal, o Estado deixa de ser o agente responsável pela garantia dos direitos trabalhistas, cabendo-Ihe um novo papel: o de diretor da "governança" 5 .

Akkari (citando VAN HAECHT, 2008) afirma que o termo "boa governança" tem sustentado as novas orientações estratégicas das políticas públicas nacionais, como "uma forma de decisão coletiva baseada na negociação e nas interações entre várias instâncias e atores envolvidos", e tem como finalidade "melhorar a eficiência da prestação de recursos públicos" (AKKARI, 2011, pp. 9092). O autor aponta ainda que, na década de 1990, o Banco Mundial foi o primeiro a utilizar a noção de good governance. O Estado assume o papel de "diretor da governança", sendo sua função regular e fomentar a competição do mercado, a fim de se garantir um "bom clima" de investimentos, promover o desenvolvimento ativo do capital humano por meio do sistema educacional e fomentar alianças regionais e transnacionais, além de realizar as metas globais, cabendo à sociedade a execução das políticas sociais (GUIDDENS, 2000, p. 57).

\footnotetext{
${ }^{5}$ No contexto neoliberal, a prescrição do papel do Estado tem sido dada pelo capital e esta tem sofrido mudanças desde a sua formulação na década de 1970. Nas palavras de Peroni e Caetano (2012, p. 3): "Enquanto nas primeiras manifestações da crise, décadas de 1970, 1980 a teoria neoliberal apregoava o Estado mínimo, nas últimas crises tem sido reforçado o papel do Estado como o administrador da crise, inclusive injetando volumosas quantias de dinheiro público dos impostos para 'acalmar os mercados' e os analistas criticando que os estados não fizeram o 'dever de casa' de diminuir os gastos públicos, leia-se direitos sociais, como se eles fossem os reais causadores das crises. O papel do Estado para com as políticas sociais é alterado, pois com este diagnóstico duas são as prescrições: racionalizar recursos e esvaziar o poder das instituições, consideradas improdutivas pela lógica de mercado. Assim, a responsabilidade pela execução das políticas sociais deve ser repassada para a sociedade: para os neoliberais, através da privatização (mercado), e para a Terceira Via, principalmente através do terceiro setor (sem fins lucrativos). [...] Os teóricos da Terceira Via concordam com os neoliberais, de que a crise está no Estado, só que apontam como a estratégia de superação o terceiro setor, que é caracterizado como o público não estatal. Assim, a tarefa de execução das políticas sociais é repassada para sociedade, em nome da participação e democratização da democracia".
} 


\section{Trabalhonecessário}

ISSN: 1808 - 799X

ANO 12, № 19 - 2014

A noção de "empreendedorismo"6 torna-se, assim, parte da agenda das políticas públicas quando se vincula aos princípios da Boa Governança, partindose da concepção de que a atuação governamental deve estar voltada para os sujeitos sociais, investindo na sua capacidade empreendedora de gerar valor para toda a sociedade. Neste contexto global de quebra das cadeias produtivas e da implementação do toyotismo, modelo fundado na subcontratação e terceirização (prestação de serviços), como também na máxima flexibilização de produtos e serviços, o Estado adota uma agenda de políticas públicas educacionais direcionadas à formação de trabalhadores dentro do paradigma do empreendedorismo. Na perspectiva do capital internacional, isso significa diminuição dos custos trabalhistas por meio da terceirização e contratação de serviço temporário, flexível, customizado; do ponto de vista do Estado da Boa Governança, isso traduz-se na atração de investimento internacional, a partir da oferta de prestação de serviços (terceirizações), por meio da capacitação de empreendedores; e sob a ótica do Trabalhador, que se converte em "dono do próprio negócio", imbuído do ideal do self made man, o seu sucesso depende apenas de sua capacidade "empreendedora".

Todavia, este quadro pode ser problematizado a partir da constatação de que o Brasil é o país que se desponta como aquele que tem o maior número de programas voltados para a formação empreendedora, ao mesmo tempo em que mais de $50 \%$ dos micro empreendedores fecham seus estabelecimentos em menos de 5 anos. Há ainda o agravante de que $99,8 \%$ dos empregos gerados no país vem dos chamados empreendedores individuais (EI) e micro e pequenas empresas, o que na realidade se configura como uma forma de auto emprego.

\footnotetext{
${ }^{6}$ No Brasil, o empreendedorismo popularizou-se a partir da década de 1990, o que contribuiu para a crescente participação das pequenas empresas na economia do país. O papel de destaque da modalidade ganhou ainda mais força com a entrada em vigor da Lei Geral da Micro e Pequena Empresa, em 2007, e da Lei do Microempreendedor Individual, em 2008. (BRASIL, 2012, p.1)
} 


\section{Trabalhonecessário}

ISSN: 1808 - 799X

ANO 12, № 19 - 2014

Isto posto, questionamos: os programas governamentais para formação empreendedora funcionam de modo a suprir os interesses dos indivíduos para que sejam capazes de criar valor para a sociedade como um todo, gerando emprego formal, renda, capacitação, competitividade, como apontam os documentos, ou de modo inverso, atendem preferencialmente aos interesses do capital internacional, por meio da profissionalização de terceirizados que proporcionará, efetivamente, redução dos custos trabalhistas, mão obra especializada que assumirá tanto os riscos da produção como ofertará serviços customizados, flexíveis, temporários, gerando na realidade trabalho precário e instável?

\section{O Empreendedorismo como Estratégia para a Condução das Políticas Sociais}

A palavra empreendedorismo foi alcunhada pelo economista Joseph A. Schumpeter (1883 - 1950). Para este pensador, no sistema capitalista ocorreria o que ele denominou de "processos de destruição criativa", processo pelo qual os velhos padrões seriam destruídos por meio da introdução de alguma inovação no sistema econômico. Esta inovação pode ocorrer por meio do desenvolvimento de novos produtos, de novos métodos de produção e de novos mercados ou pela exploração de novos recursos e materiais. Portanto, o empreendedor seria aquele que destrói a ordem econômica existente por meio da inovação, assumindo os riscos de seus empreendimentos.

O empreendedorismo atualmente é entendido como instrumento de desenvolvimento econômico e social, haja vista que o Fórum Econômico Mundial tem discutido o tema empreendedorismo de forma recorrente por considerá-lo de interesse global (DORNELAS, 2008). Tal temática tem ganhado centralidade por 


\section{Trabalhonecessário}

ISSN: 1808 - 799X

ANO 12, № 19 - 2014

um número cada vez maior de países em razão do que ocorre nos Estados Unidos, onde se encontra o maior exemplo de compromisso nacional com o empreendedorismo e o "progresso" econômico, onde o "empreendedorismo é o combustível para o crescimento econômico, criando emprego e prosperidade" panfletado por "economistas e especialistas americanos", ao afirmarem "que a resposta para a saída da crise continua sendo a mesma: estimular e desenvolver o empreendedorismo em todos os níveis" (DORNELAS, 2008, p.9):

Para Dornelas, a era do empreendedorismo, muito além de um modismo, seria consequência das mudanças tecnológicas e sua rapidez, assim como da competitividade do mundo globalizado. Isto por que o empreendedorismo estaria "eliminando barreiras comerciais e culturais, encurtando distâncias, globalizando e renovando conceitos econômicos (...). A chamada nova economia quebra paradigmas, com ideias inovadoras (...), inclusive no Brasil” $(2008$, p.6).

E a novidade reside no fato que o empreendedorismo extrapola as academias de economia e administração e passa a estar atrelado à concepção de justiça e desenvolvimento social, principalmente nos termos de combate à extrema pobreza. Serão as Organizações Multilaterais - especificamente a ONU, o Banco Mundial e o BID - as responsáveis pela elaboração e difusão de projetos que tornam o empreendedorismo uma nova estratégia para o combate à pobreza.

No relatório "Um Melhor Clima de Investimento para Todos", do Banco Mundial (2005), há um incentivo aos países emergentes a desenvolverem programas e políticas de apoio aos empreendedores. $\mathrm{O}$ documento prevê que $\mathrm{O}$ desenvolvimento do setor privado seria a chave para o combate à pobreza: 


\section{Trabalhonecessário}

ISSN: 1808 - 799X

ANO 12, № 19 - 2014

sementes para a inovação e o empreendedorismo (BANCO MUNDIAL, 2005, p. 3 - grifo nosso).

Esta agência admite o setor privado (colocando em foco as pequenas e médias empresas) como uma importante ferramenta para "empoderar" a população ao gerar emprego, ofertar produtos e serviços a preços mais baixos, resultando assim na melhoria das condições socioeconômicas de um modo geral. Com relação à condição de "empoderar", Horochovski e Meirelles (2007, p. 485) apontam que atualmente o uso desse conceito tem sido indiscriminado e também polissêmico, sendo utilizado inclusive "por sujeitos às vezes situados em posições político-ideológicas opostas".

De acordo com estes autores, numa perspectiva emancipatória, empoderar seria o processo pelo qual tanto os sujeitos como as organizações e comunidades angariariam "recursos que Ihes permitem ter voz, visibilidade, influência e capacidade de decisão (...) equivale aos sujeitos terem poder de agenda nos temas que afetam suas vidas" (HOROCHOVSKI; MEIRELLES, 2007, p. 486).

Em uma perspectiva conservadora a definição de empoderamento significa o "fortalecimento da esfera privada", ou seja, a transferência à sociedade civil das clássicas responsabilidades antes delegadas ao Estado pelo grau de complexidade e distribuição/alcance, como as demandas de saúde, assistência social e outros: "Sob argumento de fortalecer as comunidades, o empoderamento assoma como justificativa para redução da despesa pública, dos impostos e regulação estatal sobre as relações econômicas" (HOROCHOVSKI; MEIRELLES, 2007, p. 492). De acordo com HOROCHOVSKI (2006, p. 12), atualmente os neoconservadores tem se utilizado do termo para "dissimular uma combinação de individualismo antiestatal e um imperialismo empresarial fundados na defesa de valores (como) empreendedorismo (...) e capitalismo internacional de livre mercado". Como se pode averiguar, o Banco Mundial se apropria desta perspecti- 


\title{
Trabalhonecessário
}

ISSN: 1808 - 799X

ANO 12, № 19 - 2014

tiva e incorpora as ideias de Alsop e Heinsohn (2005 apud HOROCHOVSKI, 2006, p. 13), segundo as quais o empoderamento objetivamente significaria a "habilidade de um ator (leia-se empreendedor) fazer escolhas" e transitar entre "estruturas de oportunidades (...) sem coerções que inviabilizem tais escolhas".

Embasado na perspectiva das escolhas individuais e do Estado criando as oportunidades estruturais para o livre mercado, o Banco Mundial advoga que o "clima de investimento" é de responsabilidade dos Estados nacionais:

\begin{abstract}
Embora os governos tenham pouca influência sobre fatores como geografia, eles têm função mais decisiva com relação à proteção de direitos de propriedade, sistemas de regulamentação e tributação (tanto na fronteira quanto internamente), fornecimento de infraestrutura, funcionamento do mercado financeiro e mercado de trabalho e recursos de governança mais amplos, tais como corrupção. A melhoria do clima de investimento é fundamental para impulsionar o crescimento e redução da pobreza (BANCO MUNDIAL, 2005, p.5).
\end{abstract}

Denota-se que tais discursos convocam o Estado a dirigir e induzir demandas econômicas, assim como depositam a responsabilidade econômica e social aos sujeitos sociais, agora "empreendedores schumpeterianos".

\section{Empreendedorismo como Eixo de Formação para o Novo Milênio (Século XXI)}

Em artigo publicado pela Organização dos Estados Ibero-americanos (OEI), Ibarrola (Retos actuales de la educación técnico-profesional - Metas Educativas para 2021 , s/d) defende que as mudanças ${ }^{7}$ ocorridas desde a metade do Século XX impactaram a concepção de formação técnico profissional.

\footnotetext{
${ }^{7}$ Caracterizada, por exemplo, pela rapidez com que se intensificam as inovações tecnológicas; o desaparecimento de algumas ocupaçôes e a criação de novas; os efeitos da globalização
} 


\section{Trabalhonecessário}

ISSN: 1808 - 799X

ANO 12, № 19 - 2014

Segundo a autora, nos países da América Latina coexistem estruturas produtivas heterogêneas que expressam defasagem no grau de desenvolvimento tecnológico e laboral, e esta condição afeta de forma tal a realidade político-social dos países que as "referências que validam a orientação dos conteúdos necessários à formação para o trabalho tornam-se confusas e contraditórias" (IBARROLA, s/d, p. 74).

De acordo com a autora, este cenário impulsionou o microempreendimento e, portanto, fez-se necessário "ampliar a formação mais além do saber-fazer técnico e incorporar importantes aspectos de obtenção de recursos, planejamento, desenho, administração, comercialização e gestão" (IBARROLA, s/d, p.76). Além disso, segundo Ibarrola (idem, p. 74), em razão da exigência da certificação para atuar em determinadas funções, muitas ocupações na América Latina não saíram do âmbito doméstico ou objetivamente apenas alimentaram micro negócios informais de subsistência (como alimentação ou roupas para os membros da família, o cuidado de crianças e idosos), transformando-se, atualmente, em serviços profissionalizados prestado nos domicílios. Diante desta nova realidade, tem-se prescrito uma formação que impulsione o microempreendimento, "por meio de programas governamentais ou (...) combinações entre diferentes atores da formação técnico-profissional" que "incentivam" jovens ou grupos desempregados à "implementação de empreendimentos" voltados ao "auto emprego" (idem, s/d, 84). Tais programas contemplam a seguinte formação: a competência técnica segundo a especificidade da área aliada à "competência de financiamento e gestão seguindo as diferentes etapas do processo produtivo (...) até a comercialização. (...) [Em tu-

traduzidos na velocidade e instantaneidade das comunicações em escala mundial; a circulação instantânea de capitais; entre outros (IBARROLA, 2009) 


\section{Trabalhonecessário}

ISSN: 1808 - 799X

ANO 12, № 19 - 2014

do isso] o fracasso das empresas não parece ser objeto de interesse dos planejadores da FTP" (idem, p. 84 - grifos nossos).

Um dos pontos que merece destaque nesta citação reside no fato dos programas de formação se sustentarem no modelo de competências - modelo amplamente difundido pelas Agências Multilaterais para a Educação na América Latina - e que coaduna com o espírito toyotista que invade todas as esferas da sociedade.

Nos anos 1970, no Brasil, a formação técnico-profissional era de cunho pragmático, em conformidade ao modelo taylorista/fordista, portanto, adestrador e instrumental; e como característica peculiar possuía uma tecnologia de base rígida e estável, demandando em comportamentos operacionais pré-determinados e simplificados, preconizado pela demarcação entre as ações intelectuais e braçais dentro de um aparato burocrático, fragmentação e a especialização do trabalho demandando uma qualificação especializada centrada em ocupações parciais (com curta duração). Não de forma tranquila, mas objetivamente transformada ao longo da história, o processo educacional não ficaria incólume a essa modelagem organizacional fabril, assimilando tal racionalidade e separando, violenta ${ }^{9}$ e gravemente, a teoria da prática. Tal formação era adquirida por meio de cursos profissionalizantes e complementados pela formação no trabalho (KUENZER, 2007).

Com o advento do processo de acumulação flexível do capital e da microeletrônica a partir dos anos 90, passou-se a demandar, enquanto pauta para a formação do trabalhador, o desenvolvimento das competências comunicativas, do desenvolvimento do raciocínio lógico-formal, da capacidade de tomar decisões, como também de transferir aprendizagens anteriores para situações no-

\footnotetext{
${ }^{8}$ FTP: Formação Técnico-Profissional

${ }^{9}$ Entendemos por violenta a separação do processo teórico do processo prático, porquanto a história da práxis não permitir, por definição, a separação da realização material e imaterial que efetivamente promove a condição dos indivíduos da espécie humana para se tornarem seres humanos.
} 


\section{Trabalhonecessário}

ISSN: 1808 - 799X

ANO 12, № 19 - 2014

vas. No contexto da reestruturação produtiva, tal concepção formativa estendeuse por todo o mundo (globalização), provocando um amplo processo de precarização do trabalho e a retração da oferta de emprego. A máxima ventilada é que a referência de escolaridade de massa passa a não ser mais garantia de emprego. Neste cenário "a importância da educação se deslocou do projeto de sociedade para o projeto das pessoas" (RAMOS, 2011, p. 245), ou seja, a perspectiva de emprego passa a depender de atributos pessoais que seriam encarados como o foco das políticas públicas formativas.

Surge neste momento a noção de competência, uma nova versão da Teoria do Capital Humano, porquanto, em essência, ambas continuam na "busca da adequação" dos trabalhadores às mudanças do mundo do trabalho. Assim, a proposta pedagógica conhecida primeiramente como Formação Baseada em Competências (FBC) defende que "é a formação que tem que se adaptar as exigências ou requerimentos do emprego, e não o contrário, recuperando-se com ele a autêntica dimensão da formação, a de ser um instrumento para" (ARITIO, 2009, s/p, tradução nossa). Segundo Aritio (2009), na Formação Baseada em Competências (FBC) os padrões de competência se expressam em ações ou aplicações de procedimentos, tanto cognitivos como motrizes, o enfoque prioriza o saber fazer, diferentemente da educação tradicional, na qual a aprendizagem está pautada no saber, no conhecimento. Porém este enfoque não despreza a aprendizagem relacionada ao saber ser/estar, porque o "saber fazer" requer o saber, ou seja, necessita dispor de informações e dados, conceitos e teorias e, também do saber ser/estar que estaria relacionado às atitudes, valores e/ou normas para o bom desempenho das funções no trabalho (ARITIO, 2009). 


\section{Trabalhonecessário}

ISSN: 1808 - 799X

ANO 12, № 19 - 2014

Tal formação corrobora com a perspectiva de Gaulejac (2007, p. 265) na afirmação de que a finalidade da educação, fundamentado na Teoria do Capital Humano, é em realidade:

(...) produzir agentes adaptados às necessidades da economia, ou seja, 'produzir o humano' (sobre os registros cognitivos, físicos e psíquicos) conforme os mesmos processos de produção dos serviços comerciais e dos bens de consumo. $O$ assalariado deve ser adaptável e flexível para integrar permanentemente as novas competências, necessárias para a evolução dos modos de produção (grifos nossos).

Atualmente, a Organização Internacional do Trabalho (OIT), por meio da Recomendação 195 (OIT, 2004, s/p.), trata sobre a valorização dos recursos humanos e de formação, afirmando que seja "essencial capacitar as pessoas com as competências alargadas que incluam não só a formação tecnológica, mas também (...) sociais e comportamentais", principalmente pelo fato de que irreversivelmente haverá "reformas" de mercado de trabalho e dos "regimes de proteção social" (grifos nossos). Seguindo esta tendência, as Agências Multilaterais vêm fomentando a ampliação da Pedagogia das Competências na América Latina e, como afirma Briasco (2010, s/p.), o estabelecimento de critérios a respeito desta pedagogia tem legitimado sua implantação porquanto o modelo se incorporar às suas pautas.

A retórica das Agências Multilaterais conciliadas ao programa de Estado será a de um constante desenvolvimento das tecnologias e de um mercado em contínuas flutuações e incertezas, exigindo permanente atualização para o enfrentamento destes desafios, portanto, exigindo a reorientação profissional.

Vale dizer que estes "desafios":

(...) dizem respeito à condição precária do mercado de trabalho, a intensificação e a flexibilização, isto é, o arrocho salarial, a instabilidade, a rotatividade, o acúmulo de funções e atribuições, a máxima 


\title{
Trabalhonecessário
}

\author{
ISSN: 1808 - 799X
}

ANO 12, № 19 - 2014

expropriação da capacidade criativa, a terceirização e a aceitação da condição informal como autônoma e empreendedora (SELARI, 2010, p.3).

Ibarrola (2009) justifica o empreendedorismo e a preparação para o auto emprego como parte dos conteúdos de formação da educação técnicaprofissional e superior. Por outro lado, Selari $(2010$, p.3) alerta que em tempos de precarização das relações de trabalho, conforme os desafios postos ao sujeito na atualidade, encontra-se a "aceitação da condição informal como autônoma e empreendedora".

Por este conjunto de elementos pode-se entender que o foco na formação empreendedora é baseado numa perspectiva economicista cujo interesse visa incentivar e garantir a sobrevivência das Micro e Pequenas Empresas (MPEs), principalmente porque nos períodos de "estagnação da economia (...) e escassez dos projetos de retomada do crescimento industrial, em alguns setores, as MPEs aparecem como as geradoras de empregos e salvadoras da atividade econômica" (BORIN, 2006, p. 51). Assim, acredita-se que para a economia continuar crescendo de forma sustentada, o aumento da produtividade se promoverá pela "melhoria da qualidade da educação, o aumento da produtividade do setor informal e das micro e pequenas empresas" (ARBACHES, 2011).

Dornelas (2008, pp. 8-9) aponta alguns exemplos mundiais de educação empreendedora discutidos na Conferência "Educação Empreendedora na Europa", ocorrida em 2006. Conforme o autor:

\footnotetext{
- Os países da Comunidade Europeia se comprometeram a realizar uma completa reforma nos currículos da educação secundária para incorporar o empreendedorismo de forma mais efetiva nos cursos, o que deve ser finalizado até 2013.

- Na educação superior as recomendações são a sistematização de capacitação de professores para ensinar empreendedorismo de forma abrangente e não apenas com o foco na criação de empresas, o desenvolvimento de estudo de casos de empreendedores locais e regionais; (...) destacam-se os programas de miniempresas, através dos
} 


\title{
Trabalhonecessário
}

\author{
ISSN: 1808 - 799X
}

ANO 12, № 19 - 2014

\begin{abstract}
quais os estudantes criam e gerenciam um negócio durante a graduação. Um exemplo (...) indicado para ser seguido na Europa e em outros países é o do NFTE - Network For Training Entrepreneurship, iniciado nos Estados Unidos e voltado a ensinar empreendedorismo para jovens de comunidades carentes (grifos nossos).
\end{abstract}

Alinhado a esta tendência "universal", o Governo Federal brasileiro, por meio do Ministério do Desenvolvimento, tem apoiado o ideário empreendedorista fomentando iniciativas que preconizem a capacitação a essa prática. Essa proposta encontra-se relatada no "Programa Brasil Empreendedor" (1999 a 2002), apresentando o expressivo número de mais de seis milhões de empreendedores capacitados em todo o país (DORNELAS, 2008) ${ }^{10}$. Dentre os programas desenvolvidos pelo Serviço Brasileiro de Apoio às Pequenas e Micro Empresas (SEBRAE), há o EMPRETEC ${ }^{11}$, que objetiva estimular e desenvolver as características individuais do empreendedor, de forma a propiciar sua competitividade e permanência no mercado (SEBRAE, 2014). Outro programa, do Governo Federal, é o Programa Jovem Empreendedor destinado aos estudantes da rede de Ensino Médio.

Atualmente, o Brasil conta com um dos maiores programas de ensino de empreendedorismo de todo o mundo, comparável apenas aos Estados Unidos (DORNELES, 2008). Segundo dados de pesquisa realizada pelo SEBRAE descritos no documento "Taxa de Sobrevivência das Empresas no Brasil" (2011), são criados anualmente 1,2 milhões novos empreendimentos formais, dos quais mais de $99 \%$ são de micro e pequenas empresas (MPEs) e Empreendedores Indi-

\footnotetext{
${ }^{10}$ Para citar exemplos, há os casos da "Associação para Promoção da Excelência do Software Brasileiro" - conhecida como SOFTEX, uma gestora do Programa Brasileiro de Software para Exportação que beneficia mais de duas mil empresas em todo o território nacional através de uma rede formada por vinte Agentes Regionais (SOFTEX, 2014), e do GÊNESIS (Geração de Novas Empresas de Software, Informação e Serviços), que trabalhou para o fomento do ensino da disciplina empreendedorismo em universidades assim como para a geração de novas empresas de software (start-ups). Ambos, programas criados na década de 1990.

${ }^{11}$ Trata-se de uma metodologia desenvolvida pelas Nações Unidas (ONU).
} 


\section{Trabalhonecessário}

ISSN: 1808 - 799X

ANO 12, № 19 - 2014

viduais (El). Tais empresas são responsáveis por mais da metade dos empregos com carteira assinada. Somando este número à quantidade de "auto emprego" que elas geram, totaliza dois terços das ocupações existentes no setor privado da economia, sendo que $40 \%$ dos salários pagos aos trabalhadores provém das MPEs. Os números demonstram por que a sobrevivência destas empresas é tida pelo SEBRAE como "condição indispensável para o desenvolvimento econômico do país" (SEBRAE, 2011, p. 4).

A partir de dados mais recentes contidos na Análise do Emprego de Agosto de 2013, em relação à criação de empregos formais, o documento aponta que foram gerados 127.648 empregos formais celetistas no país, com as MPEs respondendo pela criação de 127.439 novas vagas (99,8\% do total), enquanto as Médias e Grandes Empresas (MGEs) extinguiram 2.463 postos de trabalho. (SERVIÇO BRASILEIRO DE APOIO ÀS MICRO E PEQUENAS EMPRESAS, 2013). (VIDE TABELA 1)

Tabela 1 - Análise do Emprego de Agosto de 2013

\begin{tabular}{|l|c|l|}
\hline & $\begin{array}{l}\text { Criação de } \\
\text { empregos formais }\end{array}$ & Porcentagem \\
\hline MPEs & 127.439 & $+99,8 \%$ \\
\hline Outros & 209 & $+0,2 \%$ \\
\hline $\begin{array}{l}\text { Criação de empregos formais } \\
\text { no Brasil }\end{array}$ & 127.648 & $100 \%$ \\
\hline
\end{tabular}

\begin{tabular}{|l|l|l|}
\hline & $\begin{array}{l}\text { Extinção de postos } \\
\text { de trabalho }\end{array}$ & Porcentagem \\
\hline $\begin{array}{l}\text { Médias e Grandes Empresas } \\
\text { (MGEs) }\end{array}$ & 2.672 & $-2 \%$ \\
\hline
\end{tabular}

Fonte: SEBRAE, 2013

Porém, este cenário é delicado, porquanto "[autores descrevem] que as empresas menores acabam por reter o maior impacto dos ajustes de produção e das crises vividas pelas empresas maiores, sendo alta sua taxa de mortalidade e 


\title{
Trabalhonecessário
}

ISSN: 1808 - 799X

\begin{abstract}
ANO 12, № 19 - 2014
informalidade" (NARETTO, BOTELHO, MENDONÇA, 2004, p. 68).
\end{abstract}

No ano de 2011, o SEBRAE "comemorou dados" (sic) demonstrando que, a cada 100 empreendimentos criados, 73 sobrevivem aos primeiros dois anos de atividade, superando as taxas dos países modelo do empreendedorismo, como a Itália (SEBRAE, 2011). Entretanto, pesquisa feita pelo IBGE em 2010 afirma que já no terceiro ano de atividade de cada 100 empresas abertas, 48 encerram suas atividades (48\% do total). Segundo a mesma pesquisa, de um total de 464.700 empresas que iniciaram suas atividades em 2007, 76,1\% continuavam no mercado em 2008 (baixa de 23,9\%), 61,3\% sobreviveram até 2009 (baixa de $38,75)$ e apenas $51,8 \%$ (...) estavam abertas, conseguindo permanecer e manter competitividade no mercado em 2010 , ou seja, quase metade $(48,2 \%)$ fechou as portas. Tomando por base o índice de sobrevivência, 58\% das empresas de pequeno porte fecharam as portas antes de completar cinco anos.

\section{Considerações finais}

Este estudo demonstra como a reestruturação do setor produtivo em escala internacional e, consequentemente, no Estado brasileiro (a partir dos anos 1990), demandou por meio da Educação Técnico-Profissional a inculcação da noção de empreendedorismo nos interstícios da sociedade civil por meio do ideário da capacitação, que se tornou a solução para as mazelas de produção e emprego, novamente atrelando a Educação a uma clássica concepção salvacionista, no sentido de geração de emprego formal. A orientação e a capacitação profissional passaram a ser concebidas como um dos fatores para o êxito das políticas públicas e privadas - no contexto da mundialização dos mercados - orientadas para um novo modelo de "desenvolvimento endógeno" dos distritos industriais locais e regionais, pelo qual o Estado e a sociedade civil devem atuar de forma 


\section{Trabalhonecessário}

ISSN: 1808 - 799X

ANO 12, № 19 - 2014

combinada com o propósito de facilitar a atuação dos investidores estrangeiros na localidade. Tanto o modelo de competências como a "disciplina" de empreendedorismo comungam da ideia de se responsabilizar 0 trabalhador individualmente em relação a sua situação, seja ela de desemprego ou de fracasso empresarial. Assim, na perspectiva do empreendedorismo e da empregabilidade, "a (in)adequação é um problema do trabalhador e a ele cabe a responsabilidade de resolvê-la". (BIANCHETTI, 2005, p. 40) Uma perspectiva bastante conveniente para se encobrir os problemas estruturais do capitalismo gerador do desemprego.

Todos os dados apresentados neste artigo descrevem as iniciativas governamentais para colocar o Brasil no rumo da cartilha empreendedorista internacional, e, para isso, a capacitação torna-se seu "carro-chefe". No entanto, medidas que lançaram, inicialmente, à sociedade civil a internalização desse ideário por meio de pacotes de fomento, como as descritas, apontam que o esforço de formar uma geração de sujeitos "auto empregáveis" não significou a permanência desses sujeitos em um período de tempo suficiente, de modo a consolidar uma perspectiva que se proponha auto afirmativa e com certa permanência.

Concretamente tais dados demonstram que a realidade econômica e social engendra este modelo de instabilidade, a partir da precarização das condições de trabalho, terceirização e subcontratação, encobertos pelo discurso ideológico da culpabilização individual do trabalhador.

\section{REFERÊNCIAS}

AKKARI, A. Internacionalização das políticas educacionais: transformações e desafios. Petrópolis: Vozes, 2011. 


\section{Trabalhonecessário}

ISSN: 1808 - 799X

ANO 12, № 19 - 2014

ARBACHE, J. Brasil precisa elevar produtividade. 7 jan. 2011. Disponível em: <http://www.unb.br/noticias/unbagencia/cpmod.php?id=82088>. Acesso em: 27 jan. 2013.

ARITIO, A. B. La Formación profesional basada en la competência. Avances em Supervision Educativa: Revista de la Asociación de Inspectores de Educación de España, Madrid, n. 7, nov. 2007. Disponível em: $<$ http://www.adide.org/revista/index.php?option=com_content\&task=view\&id=223\& Itemid=49>. Acesso em: 30 mar. 2014.

BANCO MUNDIAL (BM). Relatório sobre o desenvolvimento mundial: um melhor clima de investimentos para todos. 2005. Disponível em: <http://siteresources.worldbank.org/INTWDR2005/Resources/wdr2005_overview_ portuguese.pdf $\geq$. Acesso em: 20 fev. 2013.

BIANCHETTI, L. Curriculum vitae $\mathrm{m}$ tempos de empreendedorismo e empregabilidade. In: AUED, B. W. (Org.). Traços do trabalho coletivo. São Paulo: Casa do Psicólogo, 2005.

BORIN, E. C. P. O SEBRAE e os arranjos produtivos locais: o caso de Nova Friburgo. 2006. 247 f. Tese (Doutorado) - Universidade Federal do Rio de Janeiro, Rio de Janeiro, 2006.

BRASIL. Portal Brasil. Brasil empreendedor em números. 2012. Disponível em: $<$ http://www.brasil.gov.br/economia-e-emprego/2012/02/brasil-empreendedor-emnumeros>. Acesso em: 12 jan. 2013.

BRIASCO, I. Implementación de sistemas por competencias: recomendaciones para la acción y lecciones aprendidas. Boletin Idie, Assunción, n. 5, jun. 2010. Disponível em: <http://www.oei.org.py/idie.v2/boletin/junio_10/irma-briasco.htm>. Acesso em: 14 mai. 2013.

DORNELAS, J. C.A. Empreendedorismo: transformando ideias em negócios. 3. ed. Rio de Janeiro: Elsevier, 2008.

GAULEJAC, V. Gestão como doença social: ideologia, poder gerencialista e fragmentação social. Aparecida: Ideias \& Letras, 2007. (Coleção Management, 4). GIDDENS, A. A terceira via: reflexões sobre o impasse político atual e o futuro da social-democracia. Rio de Janeiro: Record, 2000.

HARVEY, D. O enigma do capital e as crises do capitalismo. São Paulo, SP: Boitempo, 2011.

O novo imperialismo. 2. ed. São Paulo: Loyola, 2005. HOROCHOVSKI, R. R. Empoderamento: definições e aplicações. Poder político e controles democráticos. In: ENCONTRO ANUAL DA ANPOCS, 30. 2006, São Paulo. Anais... São Paulo: ANPOCS, 2006. Disponível em: $<$ http://portal.anpocs.org/portal/index.php?option=com_docman\&task=doc_view\&g id=3405\&ltemid=232 >. Acesso em: 22. mar. 2014. 


\section{Trabalhonecessário}

ISSN: 1808 - 799X

ANO 12, № 19 - 2014

HOROCHOVSKI, R. R.; MEIRELLES, G. Problematizando o conceito de empoderamento. In: SEMINÁRIO NACIONAL MOVIMENTOS SOCIAIS, PARTICIPAÇÃO E DEMOCRACIA, 2., 2007, Florianópolis. Anais... Florianópolis: UFSC, 2007.2 Disponível em: $<$ http://www.sociologia.ufsc.br/npms/rodrigo_horochovski_meirelles.pdf>. Acesso em: 20 mar. 2014.

IBARROLA, M. Formación de profesionales de la ETP: nuevos enfoques pedagógicos. In: BLAS, F. A.; PLANELLS, J. Retos actuales de la educación técnico-profesional: metas educativas 2021. Madrid: Organización de Estados Iberoamericanos para la Educación, la Ciencia y la Cultura, 2009, pp. 73-88. Disponível em: <www.oei.es/metas2021>. Acesso em: 20 abr. 2013.

KUENZER, A. Z. Da dualidade assumida à dualidade negada: o discurso da flexibilização justifica à inclusão excludente. Educação \& Sociedade, Campinas, v. $28, \quad$ n. $100, \quad$ p. 1153-1178, out. 2007. Disponível em: <http://www.cedes.unicamp.br>. Acesso em: 17 out. 2013.

NARETO, N.; BOTELHO, M.; MENDONÇA, M. A Trajetória das políticas públicas para pequenas e médias empresas no Brasil: do apoio individual ao apoio a empresas articuladas em arranjos produtivos locais. Planejamento e Políticas Públicas, Brasília, n. 27 p. 61-115, jun./dez. 2004. Disponível em: $<w w w . i p e a . g o v . b r / p p p / i n d e x . p h p / P P P / a r t i c l e / v i e w / 51 / 54>$. Acesso em: 19 ago. 2012.

ORGANIZAÇÃO INTERNACIONAL DO TRABALHO (OIT). Recomendação sobre a valorização dos recursos humanos R195, 2004. Lisboa: OIT, 2005. Disponível

em: $<$ http://www.ilo.org/public/portugue/region/eurpro/lisbon/pdf/rec_195.pdf>. Acesso em: 15 out. 2013.

PERONI, V. M.; CAETANO, M. R. Redefinições no papel do estado: terceira via, novo desenvolvimentismo e as parcerias público-privadas na educação. In: SEMINÁRIO DE PESQUISA EM EDUCAÇÃO DA REGIÃO SUL, 9., 2012, Caxias do Sul. Anais... São Paulo: AMPED, 2012. Disponível em: <http://www.ucs.br/etc/conferencias/index.php/anpedsul/9anpedsul/paper/viewFile /1015/972>. Acesso em: 12 maio 2013.

RAMOS, M. N. A pedagogia das competências: autonomia ou adaptação? 4. ed. São Paulo: Cortez, 2011

SCATENA, C. Compliance como fator competitivo. 29 abr. 2013. Disponível em: <https://www.fnq.org.br/informe-se/artigos-e-entrevistas/artigos/compliancecomo-fator-competitivo>. Acesso em: 28 fev. 2014.

SELARI, L. S. Qualificação, competência e a comodificação da educação: o crescimento do ensino superior em Londrina-PR 2009. In: SEMINÁRIO DO TRABALHO: Trabalho, Educação e Políticas Sociais no século XXI, 8., 2011, Marília. Anais... Marília: UNESP, 2011. Disponível em: 


\section{Trabalhonecessário}

ISSN: 1808 - 799X

ANO 12, № 19 - 2014

<http://www.estudosdotrabalho.org/anais-vii-7-seminario-trabalho-ret-

2010/Leandro_da_Silva_Selari_qualificacao_competecia_e_a_comodificacao_a_e ducacao_crescimento_ensino_superior_londrina_pr_2009.pdf>. Acesso em: 3 out. 2013

SERVIÇO BRASILEIRO DE APOIO AS MICROS E PEQUENAS EMPRESAS (SEBRAE). O EMPRETEC torna o empresário mais competitivo. 2014. Disponível em: <http://www.sebrae.com.br/uf/bahia/produtos-eservicos/empretec >. Acesso em: 28 nov. 2014.

. Análise do emprego Brasil: ago. 2013. Disponível em:

<http://gestaoportal.sebrae.com.br/customizado/estudos-e-pesquisas/temasestrategicos/emprego/flutuacao-do-emprego-e-desemprego-nas-mpe/cagedagosto-2013.pdf>. Acesso em: 12 maio 2014.

. Taxa de sobrevivências das empresas no Brasil. 2011. Disponível em: <http://www.sebrae.com.br/Sebrae/Portal\%20Sebrae/Anexos/Sobrevivencia das empresas no Brasil 2011.pdf >. Acesso em: 12 out. 2013.

SILV̄ER, B. Forças do trabalho. São Paulo: Boitempo, 2005.

SOFTEX - Tecnologia da Informação Brasileira. Disponível em: <http://www.softex.br/a-softex> Acesso em 24.12. 2014. 